\title{
CORRESPONDENCE
}

\section{The ultimate question}

SIR - G.K. O'Neill's statement that we are probably alone in our galaxy (Nature 294, 25; 1981 ) is based on two different arguments one about the unlikeliness of the phenomenon of life and the second about the probability of the development of space colonies by any long-lived civilization. I show here that there is an unexpected link between the two arguments.

It may well be true that the survival of life on Earth is due to an extraordinarily lucky series of accidents by which the surface temperature remained remarkably constant. On the other hand, J.E. Lovelock's suggestion that life itself was and is responsible for the maintenance of a life-friendly temperature, is not without evidence. In his book Gaia, a New Look at Life on Earth, Lovelock wrote that the fact that the Earth's climate has changed very little since life appeared, despite variations in the output of heat from the Sun, was one of the reasons for developing the Gaia hypothesis. This hypothesis proposes that "the entire range of living matter on Earth, from whales to viruses, and from oaks to algae, could be regarded as constituting a single living entity, capable of manipulating the Earth's atmosphere to suit its overall needs and endowed with faculties and powers far beyond those of its constituent parts". In another version of the Gaia-hypothesis Lovelock calls this entity an organism, but he prefers to talk about the "Gaia system". The word "organism" is indeed confusing when, used to refer to an entity of which the constituent parts are organisms. But I see no reason why this "Earth life system" (having assumed its existence) shouldn't have the property that distinguishes living systems from dead matter, namely the capability to procreate.

O'Neill's second argument - "The development of space colonies . . . is a natural and not particularly difficult stage in the development of any intelligent civilization" can be rephrased, if we are prepared to admit that the human species and its technology is integrated in the whole of living nature, to read: "The development of space craft is a natural process in every planetary life system and will lead to the creation of independent descendants (space colonies), so to ensure the pre-existence of the planetary life system"

So - is there an association between the hypothesis of an overall "organism" and the (also hypothetical) development of space colonies? It is a question that goes beyond science, and gives us a choice between heroic antropocentrism and a more objective but difficult to accept biocentrism.

Rotterdam, The Netherlands

RoEland A. DE BIE

\section{Base mettle}

SIR - I was pleased to note that your editorial staff has at last discovered the greatest of American sports as reported in your column "Shame on New York" (Nature 5 November 1981, p.2). While your comments on the competition ". .quaintly known as the "World Series" were touching and amusing, I was surprised to note a large number of errors of fact in the column. Given Nature's reputation as a scientific journal, I am sure you will want to waste no time in correcting these.

You suggested that good players are able to hit one fair ball in three. Actually, good players will hit about 8 fair balls in 10 , with about 3 in 10 resulting in safely reaching the first base. A player who could hit only one fair ball in three would shortly be sent packing for another sport where his talents might be more appropriate to the level of play (cricket perhaps?).

You noted that the Yankees were not as skilled in catching and throwing the ball as the Dodgers. This is a strange comment on an event in which one member of the Dodgers set the all-time record for most errors (serious mistakes in catching or throwing) in the "World Series". One might also have noted that members of the New York Yankees Baseball Club, once "on base", displayed a remarkable propensity for running directly towards the Dodger player in possession of the ball. The only biological parallel I can think for this behaviour is that of certain species of whales running themselves aground and eventually perishing of their own weight. In the interests of science, Nature might humbly have suggested that representative members of the Yankees should be selected for inner ear examinations or behavioural analysis during the winter. I believe that Mr Steinbrenner has made similar suggestions, couched in rather different language.

Finally, Nature's comments on the random flight of the batted ball are completely innaccurate. Every baseball player is aware that while the flight of any individual batted ball is unpredictable, when a large sample of batted balls from any one individual is examined, certain patterns emerge. As more and more samples are taken, a pattern of probabilities (not unlike probability patterns in electron orbitals) can be assembled and a definite and nonrandom distribution becomes clear. In the case of the Dodgers, these functions fell quite frequently beyond the bounds of the playing surface. In the case of the Yankees, the result of swinging the bat was that all too often the probability function for position of the batted ball reached a maximum in the glove of the catcher.

Kenneth R. Miller

Brown University,

Providence, Rhode Island, USA

\section{Another contender}

SIR - I note the absence of contributions on systems ecology to your debate on evolution.

The branching tree is a forceful image of evolution which has proved reasonably compatible with the limited evidence of the fossil record. Recently, some palaeontologists engaged on rigorous studies of fossil lineages have come to crave some theoretical innovation which would better model the history of evolutionary progress ${ }^{1}$. They may be suspected of trying to induce innovation by creating what they consider to be favourable conditions for an ideological revolution: that is, by promoting a theory of "punctuated equilibrium" as an antithesis to

"gradualisni". So far, the rather unsurprising product gleaned from articles in your journal is that evolution can occur at varying rates ${ }^{1,2}$. It also appears that evolutionary progress by punctuation of an equilibrium does not require a qualitatively different type of evolution from that predicted by the genetic theory ${ }^{2}$.

Rates of evolution seem to depend largely on the rate of change in selective stress, which results from a changing environment: for example, the gradual evolution of a species supposes gradual change in environment. However, the range of physical environments has remained fairly uniform through time: their geography may change but this is usually accommodated by a mobile biota. New forms which evolve in small isolated populations under environmental stress are likely to be shortlived: when their isolation breaks down and normal conditions return they are likely to be out-competed by more broadly adapted and numerous "ancestor" species.

In contrast, the biological environment has a capacity for accretionary change 3 . "Gradualists"' should look to the progressive development of biological systems for their selective pressures. Proponents of punctuated equilibrium might investigate the instabilities which are likely to be inherent in such systems.

Giles MorRell

\section{Calgary, Alberta, Canada}

1. Williamson, P.G. Nature 293, 437-443 (1981) . Cronin, J.E., Boaz, N.T., Stringer, C.B. \& Rak, Y. Nature, 292, 113-122 (1981).

Sepkoski, J.J. Jr, Bambach R.K., Raup, D.M. \& Valentine, J.W. Nature 293, 435-437 (1981).

\section{Is this a record?}

SIR - A recent paper by Sadler ${ }^{1}$ shows that the stratigraphic record of geological time is very incomplete. In commenting on this, van Andel ${ }^{2}$ notes that contemporary evolutionary theorists ascribe major evolutionary steps to a jump advance or "punctuation" concentration of major change in a brief time interval.

If major change happens rapidly, and rapid events are rarely preserved in the fossil record it follows that most major evolutionary events are beyond study because they have no stratigraphic record. But the actual evidence for a punctuational view of evolution depends on literal reading of the fossil record, that is, the assumption that gaps between successive stages of the stratigraphic record are insignificant $^{3}$. If gaps represent more time than fossiliferous strata do, gradual transitions between species will necessarily appear punctuated.

Sadler himself noted: "In their treatment of the fundamental character of biological evolution, Eldredge and Gould (1972) are concerned with the completeness of the record. Unfortunately they tackle only the question of the abundance of fossils. It is equally important to determine whether the completeness of the sediment accumulation is adequate for the recognition of 'punctuations' in the fossil record that are phyletic in origin rather than indicators of sedimentary lacunae. We have attempted to quantify the sedimentary aspect; these numbers need to be matched by estimates of the duration implied by 'punctuations'."

Philip D. Gingerich

Museum of Paleontology,

The University of Michigan, USA

. Sadler, P.M. J. Geol. 89, 569 (1981)

van Andel, T.H. Hature 294, 397 (1981)

Eldredge, N. \& Gould, S.J. in Models in Paleobiology ted chopf, T.J.M.) (Freeman-Cooper, San Francisco, 1972). 